Bol. Acad. peru. leng. 49. 2010 (117-134)

\title{
RAÚL PORRAS ESCRITOR
}

\author{
Carlos Eduardo Zavaleta \\ Academia Peruana de la Lengua
}

Fecha de recepción:

$20 / 11 / 2009$

Fecha de aceptación:

$02 / 01 / 2010$

No creo que sea una novedad el juzgar a un importante historiador y crítico literario, además de insigne diplomático y viajero ilustrado, que inclusive estudió a fondo a los cronistas del siglo XVI y a otros viajeros (especialmente franceses e italianos) que vinieron al país; no es ninguna novedad, digo, juzgarlo como escritor, puesto que en esencia lo fue desde su juventud, desde antes de los veinte años, cuando se inició fundando una revista satírica, Alma Latina, dirigida por él mismo, junto con su amigo Guillermo Luna Cartland.

Además, su situación no es única dentro de la llamada "generación del Centenario", pues varios de sus miembros, entre ellos Jorge Basadre, Luis Alberto Sánchez, Porras, Luna Cartland y Manuel G. Abastos, velaron sus primeras armas en el vasto campo de la literatura.

Los primeros libros de Basadre, por ejemplo, son los de un plausible literato. Junto con el gran maestro de lengua, José Jiménez Borja, tacneño 
como él, Basadre publicó de modo clandestino y con el seudónimo de "Unos parias", el espléndido y dramático libro El alma de Tacna (1926), durante el doloroso cautivero de esa ciudad. Luego, junto con Luis Alberto Sánchez, publicó el volumen de crítica y de reflexiones titulado Equivocaciones. De esa época es su valioso y expresivo artículo "Un poeta peruano" (Rev.La sierra Nos. 13-14, Lima, 1928), texto singular que resume lo que se sabía de Vallejo hasta entonces. iY acaso sus otros libros como Perú, problema y posibilidad (1931), La promesa de la vida peruana (1943) o El azar de la historia y sus limites (1973), acaso no son meditaciones de un científico social y de un buscador de símbolos históricos, filosóficos y políticos, ofrecidos al lector en una prosa limpia y aun elegante? Por otra parte, en 1938, nos dio la más duradera y responsable antología sobre Literatura Inca (París, 1938), y además, como si fuera poco, Basadre se preparó desde joven para su vasta Historia de la República, obra señera que culminó (el tomo XIV, específicamente) con un largo poema, por cierto artístico y político a la vez, de Sebastián Salazar Bondy, uno de sus discípulos. ¿Qué gran libro de historia en el mundo cierra su curso con un poema? Sólo el de un gran aficionado a la cultura y la literatura, y justamente por ello, en los volúmenes finales también, los tomos XV y XVI, el tema ya exclusivo es la cultura y la educación en nuestro país. Quiero decir que esos jóvenes historiadores peruanos, posteriores a la primera guerra mundial, respiraban el humanismo en su plenitud, pese a brotar en la dura época de Leguía y Sánchez Cerro.

En 1928, Porras, Basadre y Sánchez convergieron al fin en la Facultad de Letras, de San Marcos, y ahí sucedieron cosas curiosas. Porras se graduó de doctor en Letras, pues por entonces enseñaba Literatura Castellana, pero muy pronto aceptó la cátedra de Historia del Perú, Conquista, y al mudarse él, Sánchez, quien acababa de publicar el primer tomo de su Literatura Peruana, se ganó esta respectiva cátedra; y en fin, Basadre, el mismo año de 1928, ingresó como profesor de Historia de la República, debido a los sucesivos éxitos de sus primeros libros.

Para concluir esta introducción, donde historia y literatura se hermanan, el propio Sánchez, entre 1928 y 1930, según confiesa, deseaba escribir novelas. Dice él: “....me sentía en mi elemento contando cuentos, 
y narrando, puesto yo frente a un sueño real o imaginario. Me sentía en el deber y con el deseo de trasmitir sus excelencias... Aunque 'excelencias' sea un término que designe lo mejor, tengo para mí que cuando se excede la medida de lo común, no importa que sea para bien o para mal... Si me equivoco, pido excusas, pero no puedo corregirme porque siento que estoy en mi verdad”. En suma, Sánchez no sólo quería ser crítico, sino también escritor, novelista, y la prueba está en que, asimismo, se especializó en "historias noveladas" (dedicadas a Garcilaso, al héroe Valdivia, el fundador, al Libertador Bolívar, a Gonzáles Prada, a la Perricholi, a Flora Tristán), quizá podamos contarle hasta once libros de este género mixto, y finalmente alcanzó su deseo y publicó de veras cinco novelas, estructuradas como tales, entre 1982 y 1989.

Dicho lo cual, y con mil perdones, entramos ahora sí de lleno en la dilatada y brillante obra de Raúl Porras. Él empezó antes de los veinte años como periodista cáustico, irónico y aun con cierta picardía, usando seudónimos para burlarse de los poderosos. Tal como dije, fundó con su amigo Luna Cartland la revista Alma Latina, y tanto ahí, como en otros periódicos y revistas, publicó lo que llamaríamos artículos domésticos, incluso políticos, y pronto del texto breve y mordaz pasó a trazar con temprana erudición y valentía el intinerario de un género volátil y valioso al mismo tiempo, El periodismo en el Perú (1921). Imagínense esta empresa bibliográfica y valorativa a la vez, cuyo germen estuvo en una conferencia pronunciada en la Universidad Popular "González Prada". Y no sólo eso, sino que se recibió de abogado y sucesivamente fue asesor para el plebiscito de Tacna y Arica, presentó un "alegato" oficial al respecto, fue nombrado profesor en el Colegio Anglo-Peruano, publicó el brillante ensayo "Un profesor de turbulencia (Sánchez Carrión '1924'), luego fue ya Jefe del Archivo de Límites de la Cancillería, y lanzó su segundo libro Historia de Limites (1926), casi al mismo tiempo que publicaba otros dos ensayos que lo señalaban, una vez más, como historiador y crítico, dedicándose a las obras de Felipe Pardo y Aliaga, y Mariano José de Arce; para finalmente doctorarse en Letras, ser nombrado fugazmente catedrático de Literatura Castellana, saludar como representante de los nuevos eruditos y bibliógrafos al famoso historiador José Toribio Medina, a su paso por Lima, y como jinete de dos o tres asignaturas juntas, continuar publicando 
su serie sobre peruanos representativos, enfocada ahora a Toribio Pacheco y José Antonio Barrenechea (su padre). Y por fin, por fin, en este ascenso asombroso e incontenible, llegar a docente universitario de Historia, en San Marcos, pero también a profesor en el Colegio Alemán, en el Colegio Universitario, previsto en el nuevo programa de reformas, y también en los Colegios Antonio Raimondi, Anglo-Peruano y Corazón de Jesús. Ya el lector casi no puede seguirle en este meteórico y múltiple ascenso, creo que único en los anales de nuestros catedráticos. Y todavía, como si algo faltara, en 1933, ya es profesor en la Católica, ya es consejero de la Delegación peruana a la conferencia de Río de Janeiro, y autor de otro gran ensayo sobre Ricardo Palma. Si el primero fue sobre "Palma satírico", ahora diserta sobre "Palma romántico" (1933).

Para entonces ya está fundada su costumbre de leer ensayos inéditos en conferencias importantes. En esa condición, como invitado especial, el público culto de Lima lo recibía con admiración y aplauso. Así sucedió primero con los temas de Palma, luego con los de Pizarro, del Inca Garcilaso, de Miguel Grau, de Raimondi, de los viajeros franceses o italianos. Uno concurría a ellas como a una fiesta de la inteligencia, pero también como a la celebración de una figura o un tema peruano, que de algún modo afirmaba nuestra personalidad nacional. Algún día habrá que hablar de este papel de gran imán, de aglutinador de la cultura peruana, que jugó Porras, y todavía más cuando se dedicó a cantar a Lima y a nuestras principales ciudades. ¡Vaya hombre pequeño y altivo, quien alzaba la cabeza, ponía el mentón a proa y surcaba el aire y crecía espléndidamente con su voz clara, emotiva, llamando a vibrar y remover las entrañas del país!

Tamaña actividad, juntar historia con literatura, y con la diplomacia, y con el periodismo, y con su enjambre de alumnos a quienes inclusive gustaba llevar en visitas guiadas por nuestras país, equivale aquí a un modelo de intelectual, rico en facetas, logrado desde su juventud, potenciado entre los veinte y treinta años, y un modelo que se ha de repetir, para suerte nuestra, todos los años por venir. Él sabía perfectamente el edificio histórico y literario que iba a construir. Lo primero había sido forjarse una "voz", un estilo, y de ahora en adelante no veremos sino nuevos frutos de su asombrosa actividad. 
Si vamos a evaluarlo como escritor, fijémonos en la forma, en el género que más repite y recoge su pensamiento. Así como cuando leemos los cuentos de Ernest Hemingway, lo más visible, lo más aparente, lo más novedoso, es el uso muy frecuente del diálogo, y si leemos los cuentos de James Joyce hay una fuerte tendencia hacia la introspección, hacia el contraste y la interrelación entre el mundo interior y el exterior, de igual modo, lo más notorio, lo más frecuente en Porras, son aquellos ensayos en que nos ofrece un perfil, o una semblanza, o el retrato de un personaje histórico-literario, que es en sí un panorama de vida y obra juntas, una apreciación y evolución de su presencia histórica o artística, y siempre juzgada dentro de la historiografía nacional o continental. Por ello, quedamos admirados de sus frecuentes y sucesivos retratos, que él llama semblanzas, por ejemplo, los dedicados a Pizarro, al Inca Garcilaso, al cronista Sarmiento de Gamboa, luego a figuras de la Emancipación como Sánchez Carrión, a escritores simbólicos como Ricardo Palma, a historiadores singularísimos como José de la Riva Agüero, o a viajeros que llegaron a estudiar y vivir el Perú como Raimondi, héroes en la guerra como Miguel Grau, héroes en la paz como Gonzáles Prada, o simples amigos del autor como Luciano Benjamín Cisneros o Ricardo Vegas García.

Sin embargo, él también se ocupa de ciertos temas que no giran en torno a una figura, que no tienen rostro, sino se dedica a algo que irradia significados, por ejemplo el nombre del Perú, o el desfile impresionante de la antigüedad prehispánica peruana (su ensayo "Mito, tradición e historia" es señero); la persecución del "alma" de ciudades como Lima o Jauja es un tema entre intelectual y filosófico, pero que nos cautiva, o géneros literarios como la sátira o la tradición en el Perú, o sino, escribir todo un tratado sobre un libro ya existente que lo deslumbra, por ejemplo, darnos un prólogo, un estudio preliminar de 162 páginas, sobre el espléndido libro Paisajes peruanos, de Riva Agüero, de 204 páginas, construyendo ambos un edificio literario - histórico de dos pisos, que es absolutamente único en la bibliografía peruana. Y por fin, entre sus obras de mayor extensión, podemos señalar una plausible historia de la literatura del Perú, con el titulo cauto de El sentido tradicional en la literatura peruana, un breviario que va desde la antigüedad prehispánica hasta mediados del siglo XX, y cuyo título original fue "Reseña de historia cultural y literaria del Perú" (1945). 
A todos estos escritos podemos, en general, llamarlos ensayos; entendiendo así el género practicado desde el siglo XVI, con el famoso francés Michel de Montaigne como iniciador, y reinventado, renovado y siempre aplaudido desde entonces. ¿Qué es finalmente un ensayo? En esta composición literaria (difundida en la historia, la filosofía, la psicología, las ciencias sociales y la ciencia en general), hay tres momentos en que el autor debe ser específico: primero, él debe ofrecer una información lo más certera y sintética posible sobre el estado de las investigaciones en la materia que él va a tratar; segundo, debe "acercar" el tema a su persona, a su talante, a su visión particular; y en tercer lugar, debe ser claro y aun valiente, a fin de ofrecer una opinión personal sobre el tema escogido, y no irse por las ramas.

Como ejemplo general y muy apropiado de ensayo en Porras podemos señalar el excelente texto "El nombre del Perú" (1951). Aquí la información, que sobre el tema ofrece el autor, viene desde la antigüedad legendaria, pero que sin duda tiene una fecha inicial histórica muy probable: el año de 1534, "después de la llegada de Hernando Pizarro a Sevilla y del desfile, ante la vista azorada de los habitantes y de los mercaderes genoveses y venecianos, del fabuloso tesoro de tinajas y de barras de oro, a que se habían reducido los esplendorosos adornos del templo de Coricancha, que sirvieron de irrisorio rescate al Inca Atahualpa. La noticia de la sorprendente riqueza del César español, corrió por toda Europa y se tradujo a todos los idiomas, para que lo entendiesen y apreciasen todos los rivales y enemigos de España, en cifras de envidia. El nombre del Perú corrió desde entonces con una vibración de leyenda".

Enseguida, viene el esclarecimiento de las fuentes existentes, se cita al Inca Garcilaso y a la cohorte de cronistas; se dan las versiones de Blas Valera sobre el presunto río Perú, la del cacique Birú o Perú, según juicios de Andagoya y Oviedo; las opiniones de Gómara y Zárate sobre las provincias del Perú, las disquisiciones filológicas del clérigo Montesinos, y hasta el nombre de Ophir. Y ya en otro momento del proceso que el mismo autor aconseja seguir, dice: "el derrotero de esta dilucidación deberá seguir por estos cauces. $1^{\circ}$ El testimonio de los cronistas que recogieron la versión directa de los descubridores y conquistadores; $2^{\circ}$ 
La discriminación cronológica[...] del momento en que se empieza a usar la palabra Perú; y $3^{\circ}$, La contribución de los escasos documentos cartográficos..."

He aquí las primeras dos fases, las de información sobre el tema y la del derrotero en la pesquisa a seguir; y finalmente, para culminar el trabajo, nos da, una a una, las dieciséis conclusiones a que llega, de las cuales desprende una opinión personal y final que dice así: "El nombre del Perú no significa[...] ni río, ni valle, ni orón o troje y mucho menos derivación de Ophir. No es palabra quechua ni caribe, sino indohispana o mestiza. No tiene explicación en lengua castellana, ni[...] en la antillana, ni en la lengua general de los Incas. Y aunque no tenga traducción en los vocabularios de lenguas indígenas, ni en los léxicos españoles, tiene el más rico contenido histórico y espiritual. Es anuncio de leyenda y de riqueza, es fruto mestizo brotado de la tierra y la aventura, y gráficamente significa tierras que demoran al sur. Es la sintesis de todas las riquezas y de la leyenda de la riqueza austral. Por ello cantaría el poeta limeño de las Armas Antártidas, en su verso de clásica prestancia: Este Perú antártico, famoso...”

Por supuesto que no todos los escritos de Porras son ensayos, ni todos lo que sí son ensayos tienen esta excelente factura de las tres tareas convergentes en una conclusión novedosa. Pero el interés es siempre el mismo: dilucidar un tema, ofrecer información válida o dudosa, someterla al "yo" personal, y finalmente deducir de modo razonable una conclusión.

Uno de sus ensayos más largos, por ejemplo "El sentido tradicional en la literatura peruana" (107 páginas) (1969), no sólo es una reseña, sino que ofrece información de dos fuentes, la histórica y la literaria, plantea un "sentido" común que perdure a lo largo del trayecto de siglos, y luego de calificar ese camino, llega a la conclusión de que "la nota más constante que surge de este[...] recorrido -al lado de la tristeza andina, de la ironía costeña, de la indolencia selvática- es el profundo tradicionalismo del hombre peruano". Y Porras pone una fecha para su juicio, 1945. 
El autor pues, cumple a cabalidad este desarrollo de sus ideas, y lo hace no sólo con precisión y aun con valentía, sino también nos ofrece algo más, el vaivén de sus emociones de observador, y de lector de fuentes. En los textos ensayísticos lo sentimos vibrar y palpitar con los temas peruanistas más caros a él, o también sonreír y celebrar un tema risible, o francamente satírico, el de los pregones y burlas a los malos gobernantes. Y todo esto se da al lector mediante una forma de escribir; desde joven él se ganó un estilo claro y preciso, y además de acomodar el lenguaje a su tema, él mismo se comunica a nosotros mediante un tono, un estado de ánimo, que invita a autor y lector, nos hace oscilar según las emociones del texto. Nunca es frío, y por el contrario, llega a tal apasionamiento por sus temas, que ilustres colegas suyos, como Jorge Basadre o Guillermo Lohman Villena le han aplaudido su estilo de herencias clásicas. Ellos primero aprecian su estilo, digno de los mejores escritores del país, y luego elogian esa continua emoción que acompaña a sus ideas. Lohman Villena llega al punto de calificarlo claramente de historiador romántico, o sea, el de la prosa encendida por el amor a la patria, a sus héroes, a las empresas más notables por el tesón, la victoria, o incluso la derrota, que enseña y moldea el carácter. Por su parte, Basadre, en el entierro de Porras, dijo en su discurso fúnebre: "Tócame hablar... de su genuino y excepcional destino de escritor, historiador e internacionalista, (tareas) que (fueron) sin duda lo que más estimaba en sí mismo... A diferencia de los eruditos, que se instalan en un área, o dentro de un período, la vocación peruanista de Porras irradió sobre todas las épocas de la historia nacional".

Luis Jaime Cisneros lo llama un "profesor de literatura" y añade: "...la vinculación de Porras con la literatura no se circunscribe a sesudas investigaciones monográficas, o a clases magistrales en la Universidad: forma parte de su condición humana... Cuando lo recordamos... comprobamos que la ironía, la armonía de su prosa, la lenta modulación de la voz... eran elementos de un cuadro total en que la literatura tenía asiento por derecho propio. Ese fervor por lo literario, signo característico de su generación, era en él como una expectativa de la sangre. Y es claro que un serio contacto con las fuentes literarias tenía que haberle ofrecido... testimonio de cómo estaba el hombre adherido a su mundo concreto... Frente a una crítica literaria incipiente, dedicada al falaz ejercicio de 
la descripción argumental o de la nimiedad biográfica, estaba Porras ya predispuesto, desde sus trabajos iniciales, a vincular vida y poesía, hombre e ideas, mundo concreto circundante y mundo íntimo de la imaginación y la literatura". Otros historiadores y críticos literarios como José Durand, o Jorge Puccinelli, piensan igual, y el joven profesor sanmarquino Camilo Fernández Cozman publicó en el 2000 un libro titulado expresivamente: Raúl Porras Barrenechea y la literatura peruana, subrayando los numerosos ensayos dedicados por Porras a los principales escritores del país.

Yo, como estudiante de literatura, tuve la suerte de servirle de secretario en dos ocasiones, en 1951, cuando se reunió en Lima el primer Congreso Internacional de Peruanistas, celebrando el IV centenario de la fundación de San Marcos, y la segunda, entre 1955 y 1956 . De aquellos años recuerdo nítidamente la forja de dos libros espléndidos, Mito, tradición e historia del Perú y su Estudio preliminar a Paisajes peruanos, de Riva Agüero. Del primer texto sobre Mito y tradición... yo saqué una copia del dictado. El original lo retuvo él y ahí mismo empezó a revisarlo y a añadirle notas manuscritas (con letra muy menuda), y así cubrió las márgenes de las cuartillas con correcciones de arriba y abajo, de izquierda a derecha, y por fin lo metió en su maletín de cuero, de solapas y hebillas, y nos fuimos por la avenida Arequipa un poco retrasados, en su viejo automóvil, y él manejando con la cabeza ladeada, para usar su mejor ojo, y al momento de ingresar en el apiñado y palpitante Salón de Grados, de nuestra Facultad de Letras, me susurró que no encontraba su original, y por ello, me exigió que le diera mi copia. Yo sólo dije "pero ahí no están sus correcciones”. Él subió al estrado en medio de atronadores aplausos; era el Presidente de la Comisión convocante, sonrió, alzó la cabeza, puso en el aire el mentón como una proa, y leyó con una perfección tan completa que incluso yo oía en su voz las correcciones que no estaban en el papel, sino en su mente.

De ese texto fascinante voy a leer un pasaje final:

...Nuestra posición en América, de país de encrucijada y con destino centralizador de núcleo. A la diversidad y fraccionamiento de su territorio y a la confluencia en él de todas las vías de 
comunicación del continente, se ha debido la convergencia de las inmigraciones pre-hispánicas del sur y del centro, y los préstamos culturales que culminaron en el aglutinamiento de tribus de la confederación incaica y en el nacimiento de la vocación continental del Perú. Esta misión de coordinación la cumplió el Perú en diversas épocas, venciendo su propia incomunicación y abrupta separación dentro de su mismo territorio; y Lima se convirtió durante el Virreinato en la capital política y cultural de América, y en la época de la Emancipación, en nudo de las corrientes libertadoras que acudieron a su seno, desde el norte y el sur, para ganar la batalla continental y decisiva en el campo fraterno de Ayacucho. Todo esto influyó espiritualmente sobre el peruano, configurando su sicología, en la que la hospitalidad para el extranjero y la sensibilidad para los ajenos dolores e injusticias, fue impulso tradicional, abierto y generoso. (p. 97)

Pasemos a otros fragmentos de dos de sus principales retratos o semblanzas: los dedicados a Pizarro y al Inca Garcilaso:

Arquetipo del conquistador, heroico, ambicioso, anárquico, Francisco Pizarro es la figura más arrogante de la conquista de América. No hay quien más a tono supiera acordar la vida con la muerte. Hombre de acción, sobre todo, que vivió continuamente en obra, destruyendo o creando, pero en perpetua actividad, sin conocer jamás el reposo absoluto ni el ocio. Y como hombre de acción, espíritu sin amarras ni raíces sentimentales, presto a desligarse de todo, sin más perspectivas que las del futuro, sin mirar nunca atrás en la propia vida ni en la de otros, fugitivo de sí mismo y de toda intimidad asentadora. Y por eso, su inquietud de crear y su falta de compromisos con el pasado. A los 46 años, mirando sólo adelante, emprende la conquista del Perú, a los 57 inicia la fundación de Lima. Ímpetu sin descanso...

Alma española, sobre todo, templada en la recia forja de Séneca. Si el estoicismo es, como se ha dicho, la filosofía natural de España, pocas almas más españolas que la de Pizarro, que no conoció los 
placeres ni tuvo necesidad de ellos, que no sintió más apetitos que los de la gloria, que temió a los afectos como a enfermedades del alma y se recató del amor y de la amistad como de una debilidad, que no sintió ni la alegría, ni el miedo, ni la compasión y muy pocas veces la ira y fue, como todo estoico, leal a su destino férreo, e incapaz de contradicciones, es decir, de arrepentimiento.

Sus juicios sobre Pizarro se basan en una documentación que el autor da por cierta y suficiente. Pero otra es su conducta cuando los datos son imprecisos y entonces el escritor avanza dudando, como en un cuarto penumbroso. Así se conduce Porras cuando trata de pintar el probable o posible retrato de doña Inés Huaylas Ñusta. El encanto de la probabilidad es, asimismo, una técnica muy usada por los novelistas:

La figura de doña Inés Huaylas Nusta, la compañera india de Pizarro, permanece... borrosa... Y es que el destino de estas mujeres indias al lado de los conquistadores fue pasivo, sumiso, y de una ternura efímera y clandestina, sin una intervención directa, afectiva o material, al lado de sus rudos dominadores. $\mathrm{Ni}$ esposas ni amantes, sino simples siervas para la caricia o el placer momentáneos; crecidas en la soledad de los acllahuasis incaicos para ser ofrendadas a la lubricidad de los capitanes del Inca o la inesperada violencia de los viracochas españoles. Tan callada, tan dulce y resignada debió de ser esta doña Inés, que pasa de puntillas por el palacio del Marqués, para que la historia no sienta sus pasos, como aquella otra india de sangre real que fue compañera del capitán Garcilaso de la Vega en el Cuzco, y cuya sombra pasa dejando un rastro de melancolía en las páginas de los Comentarios Reales....

Sigamos con los retratos artísticos y espirituales de Porras. En 1946, en su aplaudido ensayo sobre el Inca Garcilaso nos sintetiza su figura:

La característica más saltante del Inca (Garcilaso) -y en esto insurge su esencia india- es la timidez. Ella le hace vacilar largos años antes de emprender su obra definitiva, y tantear otros géneros por no 
atreverse a tomar posesión del suyo, que era indiscutiblemente el género histórico evocativo. Pero su timidez es, en parte, rebeldía reprimida, resentimiento acaso por su postergación, bastardía y mestizaje, y, en el fondo, conciencia intima de su propio valer. En La Florida y en los Comentarios reales abundan las alusiones a la injusticia de los reyes, a la privanza de los aduladores, y a las virtudes que deben tener los que mandan. No obstante el desconocimiento y menosprecio existente en su época por los mestizos, él se jacta de llamarse tal, “a boca llena”, porque fue nombre que le impusieron sus padres y está orgulloso de sus dos herencias, indígena y española. Como tal irrumpe en el escenario con su modestia ingénita, por la puerta más pequeña, esbozando tan solo unos comentarios o glosas, que van a ser no solo magistral historia, sino la epopeya en prosa de su raza y de sus parientes oprimidos.

Y ahora pasemos a un fragmento del "Estudio preliminar" de Porras al volumen especialísimo de Riva Agüero, Paisajes peruanos. El libro conjunto que los reúne vale como una prueba innegable de que algunos historiadores peruanos han salido del campo de la Historia para conseguir una luz de apoyo a la comprensión de sus textos; y aquí, exactamente, la dedicación al estilo y, en general, a un lenguaje elegante y notorio, quiero decir visible siempre, logra iluminar el texto, que se convierte en doblemente valioso, pues las ideas conllevan inclusive valor estético. En el siguiente texto, Porras comenta la dedicación de Riva Agüero a pintar literariamente el paisaje, a colorearlo como si el original no fuese suficientemente bello. Leamos:

Riva Agüero es también maestro en el manejo del color... Se adivina en esta maestría la influencia literaria romántica y francesa, no solo la de Chateaubriand y de Fromentin..., sino quizá mucho más poderosa y sugestiva, la de Gautier en su Viaje a España y la de los (hermanos) Goncourt. De ellos aprendió Riva Agüero la seducción por los matices intermedios e imperceptibles para el ojo vulgar y su asociación o analogías con otras tonalidades desapercibidas de la naturaleza, en plan de metáfora o de irónico 
paralelismo. Esa técnica pictórica es la usada por Riva Agüero para dar la sensación de cada uno de los complicados juegos de luces y colores de los paisajes andinos. 'El paisaje - dijo Chateaubriand no ha sido creado sino por el sol; es la luz la que hace únicamente el paisaje'. Y Riva Agüero persigue las más leves tonalidades de los amaneceres, del mediodía, o del crepúsculo, para trasladarlos intactos a sus notas de viaje.

Lástima que no podamos añadir sus reflexiones sobre la llamada ‘descripción del paisaje sonoro' en Riva Agüero, donde se confunde la voz del viento con el campanilleo de las mulas, con el ladrido de un perro, con el ruido torrentoso del Apurímac, 'como el rugir de una fiera herida', con la clarinada de los gallos o el sollozo de las antaras.

Leamos ahora un fragmento del discurso de Porras sobre "Palma romántico” (1933):

Palma recogió desde niño la emoción de la historia. En sus andanzas colegiales de novillero se había encontrado muchas veces frente a vivos símbolos del pasado. Un día, en una huerta cercana de la quinta de Presa, había conocido a un negro tejedor de cestas, que tenía una jauría de perros bravos y que se descubría al hablar del 'rey nuestro amo'. Era Pancho Sales, antiguo verdugo de los virreyes. Otro día siendo niño, vería descender de un carruaje a una mujer de rara y melancólica belleza y sabría por un compañero que era María Abascal, presunta hija de un virrey y reina en su tiempo del amor y la hermosura. $\mathrm{O}$ ya junto a una mesa, en el mercado próximo a su casa, haciendo oficio de carnicería, tuvo ocasión de ver y hablar con Juana la Marimacho, la audaz capeadora en los días suntuosos de los toros de la Concordia. Pero la más genial de las suscitadoras del pasado era la limeña de saya y manto. Radiguet ha dicho que el traje de las tapadas daba a la ciudad de Lima el aspecto de un baile de máscaras.

Y de esta vieja escena de tapadas y máscaras, pasemos a quien asimismo la recreó, en una dedicación perdurable al espíritu, al "alma" 
de Lima, pues sin duda para entender a las grandes ciudades hay que reconocer su magia etérea, invisible pero real. Porras dice sobre Lima:

"Algo hay, en efecto, de impalpable, pero de real; desvanecido, pero presente; algo que bien pudiera ser la huella de los más culminantes momentos de su vida o acaso tan solo una sugestión histórica hallada en los libros; pero es lo cierto que, extraños y nativos, hallan en la fisonomía de la ciudad, en el ambiente de sus calles o de sus rincones antiguos, una como extraviada nostalgia. El pasado vive y persiste en Lima, y atrae con fuerza innegable. Todo en ella tiene una historia. El nombre de una calle, la inscripción de un muro o de un frontispicio, perpetúan un episodio, nimio o característico, conocido u olvidado, pero con un fondo de vida que se aferra, con ansias de no perecer, a algún último vestigio. Historiadores y cronistas han exaltado, extendido y pormenorizado ese culto por la leyenda de la ciudad, al punto que ella constituye todavía su gala mejor y más genuina.

Pero, no sólo en la tradición residió el atractivo y perdura el alma de Lima. En el carácter ligero y burlón de sus habitantes, en la fina gracia de sus mujeres, en el malicioso ingenio y la agudeza de los limeños, señalaron los viajeros la nota más típica y local de nuestra espiritualidad. Fuera redundancia insistir en el elogio de esa sal criolla que se derrocha en las calles y en los papeles, en los labios y en la pluma, y que hace que conversaciones y versos y periódicos trasciendan siempre un poco a epigrama.

Nos queda poco tiempo, pero suficiente para citar otros breves fragmentos inolvidables y dedicados, por ejemplo, a Miguel Grau y a Antonio Raimondi, uno, héroe en la guerra y otro, héroe en la paz, figuras al parecer distintas, pero muy similares porque ellos significan dos clases de docencia, dos figuras pedagógicas excelentes para moldear el carácter del peruano, el heroísmo, a un lado, y la pasión por la ciencia, por otro.

Grau fue y será... el símbolo del Perú, el héroe peruano por excelencia, porque tuvo entre sus virtudes cardinales algunas 
que eran suyas, como brote milagroso del genio heroico -salud, fortaleza, tenacidad, prudencia, robustez del cuerpo y del alma-, y otras que eran la impronta de nuestro espíritu y nuestro sino, y cristalizaron en su mezcla de bravura y nobleza, en su humanidad y ternura para el niño o para el enemigo, en su incapacidad para la violencia destructora y la saña vandálica, y sobre todo, en su peruanísima lección de vencer sin odio y de perder con honra.

Raimondi es un hombre síntesis de nuestra cultura. En él se funden, bajo una ejemplar modestia, todos los tipos de viajeros precedentes; tiene la intrepidez y la abnegación del explorador español, el desinterés y el halo apostólico de los misioneros católicos, la minuciosidad histórica de los cronistas y el rigor científico de los más avezados viajeros sajones o tudescos. Su obra guarda por esto la mayor suma de peruanidad, y es superior en lo que respecta al Perú, a la de Cieza, a la de Acosta, y a la de Humboldt, los grandes coordinadores de nuestra ecúmene, y se parangona únicamente, desde el campo de la geografía, con la de Garcilaso y de Palma, en la historia y en la literatura.

Finalmente, acortando a la fuerza esta inconclusa relación de textos, debo citar unas páginas autobiográficas, en que Porras recuerda a dos de sus entrañables amigos, el abogado Luciano Benjamín Cisneros (defensor de Miguel Grau en los tribunales), y Ricardo Vegas García, ex diplomático, a quien Porras llama "su mejor amigo". Como se verá, aquí el tema del ensayista cambia hacia la intimidad más privada, hacia el temblor del corazón humano:

Fue Luciano Benjamín Cisneros; el defensor de Grau cuando se le acusó por su rebeldía honrada y consciente de "traidor a la patria”, el tribuno que pagó su fe democrática con la prisión y la amenaza de las turbas azuzadas por el poder, el gran orador que encarnó, después de la guerra, por plebiscito nacional, el verbo de la reivindicación de nuestras ciudades cautivas, quien en el 
momento de la absurda incidencia que ensombreció mi hogar y cubrió de duelo toda nuestra infancia, cuando mi padre cayó victimado en una de esas encrucijadas que llaman del honor, clamó en la tribuna judicial y en la prensa por la sanción contra los responsables del delito, escribiendo entonces con aliento romántico y lamartiniano, sin odio ni rencor, a puro sentimiento, una página que es acaso su mejor oración, en el sentido de piedad, titulada El dolor de la viuda y que guarda todavía, por la perennidad del arte y de la sinceridad, el desgarramiento interno de la tragedia, probando así que, en las clasificaciones de su profesión, que él mismo hizo alguna vez, prefirió siempre ser gran abogado más que por el valor de la inteligencia o de la doctrina, por la nobleza del corazón.

\section{$-\mathrm{O}-$}

La lección de Vegas es la de la energía para defender la propia convicción, la de la lealtad a su solar nativo, y, a la vez, la curiosidad por lo universal y humano, la de la consagración absoluta y desinteresada, heroica casi, a las tareas del espíritu y, sobre todo, la de la nobleza del corazón. Podría decirse que él puso el corazón por delante en todas sus empresas y que todos sus actos denuncian en él -como decía Unamuno- una "lógica cardiaca”, una lógica del corazón, que llena y reemplaza los vacios de la lógica nacional con la profunda sabiduría de los mejores impulsos vitales. No tuve ni tendré mejor amigo que Ricardo Vegas García y, en los recuentos de mi juventud y de este atardecer sin esperanza, surge la imagen de su ánimo enhiesto y denodado, de puro sentido caballeresco, repartiendo mandobles contra galeotes y yangüeses, y rindiéndose únicamente ante una dulce imagen femenina.

Una pequeña nota antes de pasar a la página final.

¿Por qué ahora, a los 48 años de la muerte de Porras, sólo ha aparecido un tomo de sus Obras completas? Aunque no querramos, podemos mirar 
el ejemplo de la Universidad Católica, que no solo ha editado y difundido con devoción más de una docena de gruesos volúmenes de don José de la Riva Agüero, otro maestro sanmarquino cuya suerte editorial es muy distinta. ¿Qué hace hoy en día un admirador de Porras? Pues conseguir un pequeño libro aquí, otro pequeño libro allá, en variadas ediciones que merecen un ordenamiento y una presentación acordes con su prestigio intelectual. ¿Cómo es posible, por ejemplo, que su grueso volumen sobre Pizarro desmereciera en su aspecto, publicado groseramente y envuelto en avisos comerciales? ¿Cuándo tendremos otra edición? ¿A quién podemos pedir que este descuido se repare alguna vez? Todos sabemos que el encargo recayó por vía directa o indirecta en nuestra Universidad de San Marcos; no queremos abrumarla en pedidos, ahora que está toreando con un miura difícil en su problema de pistas, pero a medida que pasen los años, la responsabilidad de no cumplir con el prestigio de Porras recaerá sobre alguna institución.

Y nada más. El tema de Porras escritor, repito, no es nuevo, ahí están los ensayos de Lohman Villena, Luis Jaime Cisneros, Jorge Puccinelli, José Durand, Luis Loayza, Wáshington Delgado, Andrés Townsend Ezcurra, Camilo Fernández Cozman; pero todos ellos son uno por uno iniciales, primerizos, y necesitamos una dedicación más calmada y pensativa. $\mathrm{Si}$ Porras no hubiera tenido alma de escritor, no hubiese expresado tan bien las esencias de Garcilaso o Palma, o de los satíricos, o de los pensadores de la emancipación y la república, ni menos hubiese desentrañado el difícil y fascinante lenguaje de los cronistas, y tampoco nos hubiera ayudado mucho en la ordenación, comprensión y difusión de Poemas humanos, el libro esencial de Vallejo. En su otra faceta de crítico literario, él fue más justo y despierto que muchos supuestos especialistas. Él veía la literatura como un importantísimo pilar en el edificio del Perú.

Verlo como escritor desde su juventud, facilita la comprensión de sus facetas, y su deliberado afán de llevar a la historia y al ensayo el fervor por el arte literario. Sobre cualquier tema suyo, brilla la palabra adecuada, el ingenio espontáneo, la frase balanceada, el párrafo en busca de las esencias, pero también la sonoridad rítmica y musical. Nada de oscuridades barrocas con él. 
¿Cuál era, en suma, el estilo de Porras? Lejos de la vieja oratoria ramplona, del cascarón sonoro, forjó un discurso pleno de reflexiones y sugerencias, de claridad cartesiana, pero, en una mezcla muy personal, asimismo emotiva, quizá incluso romántica, pero sólo en su entonación, pues el autor era infatigable en la búsqueda de pruebas objetivas. Sus frases ascendían desde la serenidad, luego recibían diversas cargas de emoción (respeto, nostalgia, ternura, burla, tristeza, o también condena, rechazo, y así llegaba al nuevo estado de las cosas bien explicadas, produciendo inclusive alegría o euforia), hasta alcanzar una declamación vibrante, una invitación al público a entrar como personaje en la historia de un héroe, en la fundación de una ciudad, en las peripecias o triunfos de un viaje, o en el oscuro pasado de la leyenda o el mito. Una declamación efectiva por el gran aliento, la gran respiración de Porras el orador, quien, paradójicamente, agonizó incapaz de respirar por su débiles pulmones.

\section{Correspondencia:}

\section{Carlos Eduardo Zavaleta}

Miembro del Consejo Directivo de la Academia Peruana de la Lengua.

Correo electrónico: carlos.eduardo.zavaleta@academiaperuanadelalengua.org 